Sharif University of Technology
Scientia Iranica
SCIENTIA
IRAN I CA
http://scientiairanica.sharif.edu

\title{
Core impact force of vertical water jets on smooth and rough surfaces
}

\author{
M. Fathi-Moghadam ${ }^{\mathrm{a}, *}$, A. Salemnia ${ }^{\mathrm{b}}$, and S. Kiani ${ }^{\mathrm{a}}$ \\ a. School of Water Science and Engineering, Shahid Chamran University of Ahvaz, Ahvaz, Iran. \\ b. Department of Water Engineering, Sari Agricultural Science and Natural Resources University, Sari, Iran. \\ Received 18 February 2017; received in revised form 15 July 2017; accepted 11 September 2017
}

\section{KEYWORDS \\ Breakup length; \\ Falling height; \\ Pressure coefficient; \\ Turbulence intensity; \\ Vertical jet.}

\begin{abstract}
A normal way to dissipate energy of the dam-released high-velocity jets is to allow them to free-fall into a plunge pool or impact a plane surface in case of dam site limitations. The water jets have an undisturbed core from nozzle outlet to a certain falling height, which has more impact force and less turbulence intensity than the developed part of the free jet. Experiments have been conducted to determine core impact pressure coefficient of a vertical jet on smooth and rough plane surfaces. The experiment results for different jet diameters and falling heights have shown considerable increase in the mean dynamic pressure coefficient with increase in the jet Froude number for both smooth surface and rough surface. In this study, a simple Froude based mathematical model had correlation in the estimation of jet core impact force on the smooth and rough plane surfaces. A considerable increase in the jet core length was observed with increase in the jet Froude number. Results also showed a strong correlation between turbulence intensity coefficient and the jet core length.
\end{abstract}

(C) 2019 Sharif University of Technology. All rights reserved.

\section{Introduction}

The safe flood release structures and bottom outlets are among the most important issues in design and positioning of structures and installations downstream of dams. A considerable amount of energy and momentum exchange in these outlets could lead to damages to the dam and subsidiary structures. A normal way to dissipate this energy is to release water jets horizontally into the air and allow them to dive in a plunge pool. In this case, a long falling length allows air entraining and breaking the jet core, and developing

*. Corresponding author. Fax: +98 6133365670

E-mail addresses: mfathi@scu.ac.ir (M. Fathi-Moghadam);

aminsalemnia2@gmail.com (A. Salemnia);

sajad.kiani508@gmail.com (S.Kiani)

doi: $10.24200 /$ sci. 2017.4522 the jet body before entering a plunge pool. In the cases that the downstream gorge is too narrow and curly, horizontal jets may impact and damage the gorge walls and downstream dam structures. For example, in a report by Fathi-Moghadam [1] to Khuzistan Water and Power Authority (KWPA) of Iran, the horizontal length of the jets released from the Dez dam (located in south-west of Iran) low-level outlets was estimated to be $160 \mathrm{~m}$ for a water level of $95 \mathrm{~m}$ above the center of the 4-m diameter outlets. The estimation was based on a 1:40 scale Froude based experimental modeling conducted by Acres International Corp in Canada Centre for Inland Water (CCIW) laboratory, located in Burlington, Canada. Using USBR [2] and Kawakami [3] equations, similar horizontal distance was calculated for the low-level outlets. This horizontal distance was long enough to impact the narrow gorge wall and downstream dam structures. It is worth noting that the Froude based modeling as well as the 


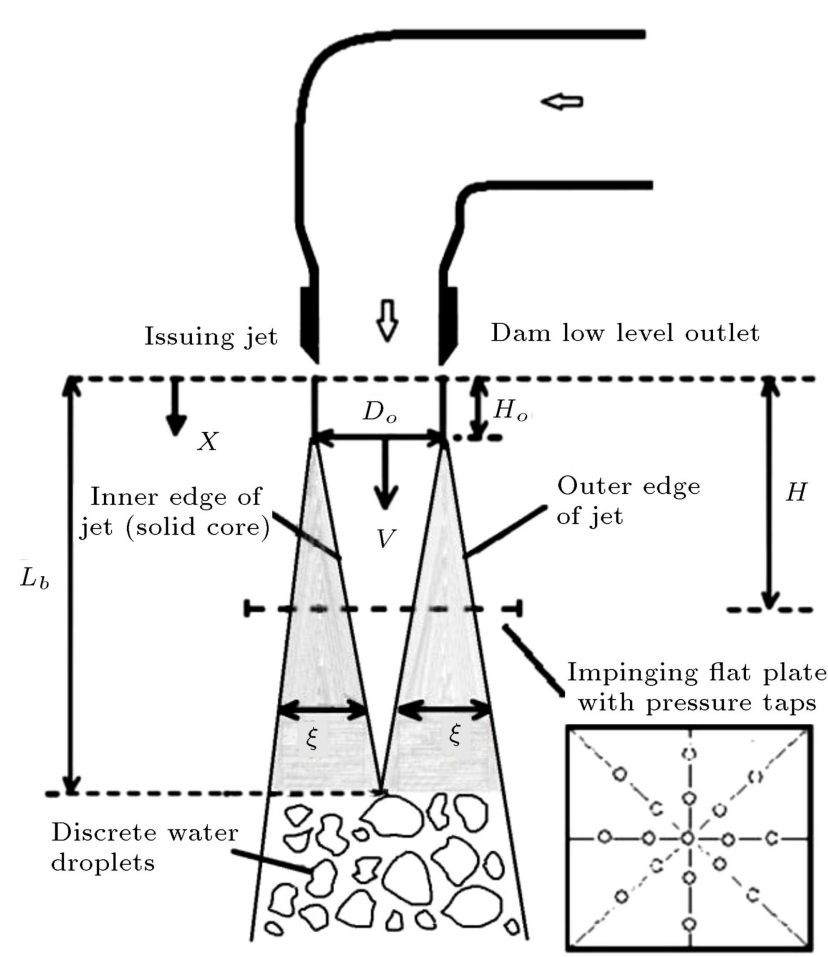

Figure 1. Schematic of free vertical water jet regions and position of flat plate in core zone (jet issuing vertical pipe is not in scale).

aforementioned equations does not account for the air friction and entrainment effects that will reduce the jet horizontal distance in field and practice.

In the next case on which this study is focused, the jet may be redirected to a vertical falling position and forced to impact a plane concrete or rock surface before being entirely developed (i.e., a core impact state, Figure 1). Design of impact plane surface requires correct estimation of the desired dynamic pressure. The estimation of jet breakup length $\left(L_{b}\right)$ and falling height $(H)$ is also important in order to determine whether the impact is in core zone or in jet developed zone. The jet breakup length $\left(L_{b}\right)$ is a vertical distance between the jet issuing level and the level where the jet is completely developed (Figure 1). The developed level is a level where the crystal clear core no longer exists, and air is entrained in the whole jet body (the discrete water droplets zone in Figure 1). It should be noted that the dynamic pressure of the solid jet impact in core zone is much higher than those in the breaking and developing zones of the jet. Contrariwise, the fluctuation of pressure in the developed zone is much more than that in the core zone due to turbulence. Therefore, turbulence intensity of the jet core is much less than that in the developed zone of the jet.

Lencaster [4], Cola [5], and Beltaos and Rajaratnam [6,7] were the first to study central pressure of the vertical and circular jet impacts on a plane surface. A fundamental understanding of the jet core length, for developed and undeveloped jets, and deceleration of the jet under the influence of air resistance can be found in [8-11]. Ervine and Falvey [12] and Ervine et al. [13] examined and compared dynamic pressure fluctuations and effects of air entrainment in free-falling jets issuing from circular and rectangular nozzles. Using systematic experimental results, the influence of the air entrained by water jets on the dynamic pressures applied to the bottom of a plunge pool and inside underlying fissures was analyzed by Duarte et al. [14].

Rock scour and erosion of plunge pool due to impact of high velocity jets is also of particular interest and has been studied in [15-19], considering water depth in the pool. Kerman Nejad et al. [20] studied dynamic pressures induced by flip bucket jets on the submerged horizontal and inclined surfaces. They found that the largest pressure fluctuations as well as the highest average fluctuations occurred at the 90-degree angle of impact. The dynamic pressure and pressure fluctuations decreased by decrease in the impact angle. Ervine and Falvey [12] presented a theoretical equation to find the jet breakup length and showed that the most important parameter in jet breakup length was turbulence intensity coefficient $\left(T_{u}\right)$. They verified their theoretical equation with experimental results.

Ratio of falling height to the jet core length $\left(H / L_{b}\right)$ is a parameter to determine state of the jet development. Castillo [9] conducted experiments at various jet Froude numbers and falling heights to produce a range of $0.5 \leq H / L_{b} \leq 0.9$ in his study. Puertas [21] produced a range of $0.5 \leq H / L_{b} \leq 3.1$ in his experiments using four falling heights of 1.85 , $2.88,4.43$, and $5.45 \mathrm{~m}$ and different Froude numbers for various plunge pool depths. Castillo [15] measured the dynamic pressures on an array of plunge pool bed using pressure transmitters with sampling rate of 20 measurements per second. In addition, Castillo [22] and Castillo et al. [23] presented four states of jet impact considering core and developed jets for shallow and deep plunging pools. They suggested a series of relationships between the pressure coefficient and the jet breakup length. In the following studies, Castillo et al. [24] investigated velocity and turbulent kinetic energy distributions in different cross sections of a plunge pool located downstream of the jet impinging point. The result indicated that energy dissipation in the plunge pool was between $75 \%$ and $95 \%$. Furthermore, studies related to reliability of numerical models to estimate the scouring downstream of the plunge pools were carried out by Castillo and Carrillo $[25,26]$ and $\mathrm{Li}$ et al. [27].

To date, numerous water jet impact studies have been devoted to plunging of the developed jets in plunge pools. However, a critical state of impact may 
arise in the case of core impact on a bare bed or a very shallow pool, which is proposed in this study. To determine the state of development, the jet breakup length must be estimated using jet Froude number and jet turbulence intensity coefficient. The purpose of this study is to estimate mean core impact pressure of a vertical jet on smooth and rough bar surfaces and weight of the jet Froude number as governing parameters. Relation of turbulence intensity coefficient and the jet breakup length with Froude number is also discussed.

\section{Materials and methods}

\subsection{Theory}

By definition, the water jet is a turbulent flow generated by a continuous momentum source. Water jets with different Froude numbers and falling heights may be in different states at the moment of impact with a surface or entering the plunge pool. They may be completely broken up (called developed jet) and enter the pool in fully turbulent form and no core, or in the form of having a solid core with higher impact pressure. The complicated nature of the core impact jets on a bare surface urges that experiment and physical modeling be conducted in order to understand jet behavior and parameterize the impact dynamic pressure.

Jet behavior depends on various flow parameters of velocity, viscosity, and density, as well as the nozzle diameter and falling height. For water jets, velocity and nozzle diameter in the form of jet Froude number along with falling height are governing parameters. Figure 1 shows details of three main zones of a vertical water jet and positioning of a flat plane surface in core zone for later discussion of core impact in this study. However, in $H_{o}$ zone, the flow is fully solid and crystal clear with the same area as the issuing jet area. From $H_{o}$ to $L_{b}$, instabilities appear on the jet surface. At the beginning of this region, waves are regularly formed in short intervals. Formation of these waves is accelerated in the flow direction and creates the jet peripheral vortices. Transition of the peripheral vortex mode to a fully turbulent jet flow starts from this region [13]. Davies [28] showed that turbulent surface disorder $(\xi)$ was directly proportional to the square root of the falling distance as follows:

$$
\xi \propto \sqrt{X}
$$

where, $X$ in Figure 1 is the distance from $H_{o}$ to $\left(L_{b}-\right.$ $H_{o}$ ).

Finally, there is a region where peripheral turbulence intensity is large enough to overcome surface tension and establish a considerable air entrainment that can penetrate into the jet core and break the whole jet. This zone is called discrete water zone and the jet is a developed jet (Figure 1).

The average velocity and dynamic pressure are relatively high while velocity and pressure fluctuations are relatively low in $H_{o}$ zone and solid core of the $L_{b}-$ $H_{o}$ zone compared to the breaking zones. Therefore, by definition, the turbulence intensity is low in the $H_{o}$ and core zones and high in the broken up zones. It is worth noting that the lengths of $H_{o}$ and $L_{b}-H_{o}$ in larger scale models and practice are shorter than the similar lengths estimated from the Froude based laboratory modeling. This is due to air friction and entrainments that are not encountered in the study by Fathi Moaghadam [1].

The jet is a continuous mass before the breakup point. There are two factors affecting the jet diameter. The jet is expanded due to turbulence and contracted due to the gravitational acceleration. Ervine and Falvey [12] presented an equation for estimation of the breakup length $\left(L_{b}\right)$ of circular jets as follows:

$$
\frac{L_{b}}{D_{0} F_{1}}=\frac{1.05}{C^{0.82}}
$$

where, $D_{0}$ is the jet diameter and $F_{1}$ is the jet Froude number, which is defined as follows:

$$
F_{1}=\frac{V}{\sqrt{g D_{0}}},
$$

and $g$ is gravity acceleration, $V$ is average issuing jet velocity, and $C$ in Eq. (2) is a turbulence parameter, which is introduced as follows [12]:

$$
C=1.14 T_{u} F_{1}^{2},
$$

where, $T_{u}$ is called turbulence intensity calculated as follows:

$$
T_{u}=\frac{u^{\prime}}{V},
$$

and $u^{\prime}$ is the root mean square of velocity fluctuation. Turbulence intensity is a scale to characterize the turbulence. As stated before, turbulence intensity of the jet core is much less than that for the developed zone of the jet. However, velocity fluctuation $\left(u^{\prime}\right)$ can be calculated from the recorded pressure fluctuation $\left(h^{\prime}\right)$ at jet outlet. Arndt and Ippen [29] showed that the following relationship could be used to calculate velocity fluctuation from the corresponding pressure fluctuations:

$$
\sqrt{\overline{{h^{\prime}}^{2}}}=\rho \cdot V \sqrt{\overline{{u^{\prime}}^{2}}} .
$$

In Eq. (6), $\rho$ is water density. They stated that maximum error in the above equation was approximately $5 \%$ for a turbulence intensity of up to $10 \%$. 
A mean dynamic pressure coefficient $\left(C_{p}\right)$ is normally presented to calculate impact pressure of the jet for the case with plunge pool [12]. For the case of this study, it is presented for calculation of mean impact pressure on the flat plate in Figure 1 using the dynamic pressure head $\left(H_{m}\right.$, in meters) by transmitter as follows:

$$
C_{p}=\frac{H_{m}}{\frac{V_{j}^{2}}{2 g}},
$$

where, $V_{j}$ is an estimated jet velocity immediately before impact $(\mathrm{m} / \mathrm{s})$ calculated as follows:

$$
V_{j}=\sqrt{V^{2}+(2 g H)}
$$

where, $V$ is issuing velocity of the jet and $H$ is falling height of the jet $(\mathrm{m})$ in Figure 1.

\subsection{Experimental setup}

The experiments were conducted in Hydraulic Modeling Laboratory of Water Science and Engineering School of the Shahid Chamran University of Ahvaz, Iran. Figure 1 shows the experimental setup, including a $10-\mathrm{cm}$ diameter jet issuing pipe with a smooth collar at the end to produce a solid, turbulence-free jet. The jet profile, along with core and turbulence propagation zones, and position of the impinging flat plate are also shown in the figure. Four different discharges (ranging from 4 to 21 lit/s according to the nozzle diameters); five falling heights $(H)$ of $8,15,25,35$, and $60 \mathrm{~cm}$; and four different nozzle diameters of $4.1,4.3,5.1$, and $7.9 \mathrm{~cm}$ were examined in this study. The jet impacted a $0.5 \times 0.5 \mathrm{~m}$ flat Plexiglas plate having 17 opening tap (Figure 1) connected to a piezometric board by 0.25-inch plastic tubes. The piezometer that showed the pressure in each experiment was then connected to a pressure transmitter to measure instantaneous dynamic pressure and fluctuations. Pressure transmitters of type WIKA, model S-11, were used to measure instantaneous pressure with sampling rate capability of $10 \mathrm{kHz}$ and accuracy of $\pm 0.01 \mathrm{~m}$. In addition, to estimate initial turbulence intensity, a pressure transducer was installed at the jet outlet to measure pressure fluctuations. The pressure fluctuation was recorded in a frequency of 200 readings per second for a 1-2 min time interval. The impact pressure was normally the highest in the center or a near-center tap, and was gradually reduced in the outer taps. An acoustic flowmeter was installed on a pipe long enough before the nozzle to measure the discharge and calculate average jet velocity $(\mathrm{V})$. The jet impacted on the flat plate perpendicularly as shown in Figure 1. Eqs. (2) to (6) were used to calculate the core length for positioning of the flat plate in the desired core zone.

\section{Results and discussions}

\subsection{Jet breakup length}

As stated in the previous sections, falling jets have a dense core from the issuing point to a certain height. Due to high impact force of the core relative to developed jet, the estimation of the jet core length (or jet breakup length, $L_{b}$ ) is required for design of plunge pools or elevation of impact plane surface in the present study. Breakup length and Froude number are calculated from Eqs. (2) to (6). Figure 2 reveals the effect of jet Froude number on the jet core length $\left(L_{b}\right)$ for falling heights $(H)$ of $8,15,25,35$, and $60 \mathrm{~cm}$. All figures confirm considerable decrease in $H / L_{b}$ with jet Froude number to a point before $F_{1}=$ 20. For a constant $H$ and issuing jet velocity $(V)$, this means that the jet breakup length increases with increase in Froude number or, in fact, with decrease in jet diameter. This is true because smaller jet diameters have lower Reynolds numbers as well as lower velocities and pressure fluctuations; thus, they are more stable and have higher core lengths than the larger jet diameters in Figure 2.

\subsection{Mean dynamic pressure coefficient: smooth surface}

Eqs. (7) and (8) were used to calculate mean dynamic pressure coefficients due to impact of the jet on a bare flat plate located in the core zone of the jet in Figure 1. The pressure coefficient $\left(C_{p}\right)$ did not reveal a significant variation due to variation of falling heights $(H)$ in core zone (Figure 3(a)-(e)). Interestingly, the pressure coefficient did not change considerably with Froude number variation for a particular jet diameter in the figures. In addition, significant decrease in pressure coefficient $\left(C_{p}\right)$ was observed in all figures due to increase in the jet diameter. On average, $C_{p}$ varied from 0.90 to 0.95 for small jet diameters (or for the jet Froude numbers around 10). Moreover, the mean pressure coefficient $\left(C_{p}\right)$ was shown to be around 0.60 to 0.65 for large jet diameters (or for jet Froude numbers around 5). First, this shows that the state of impact did not change during experiments, and all impacts and dynamic pressure measurements were in the core zone. Second, the jet Froude number was a unique parameter to designate the jet diameter, velocity, and hence, the jet state of impact. The largerdiameter jets have smaller Froude number and less core stability, thus less mean dynamic pressure coefficient.

\subsection{Mean dynamic pressure coefficient: rough surface}

Salemnia [30] conducted similar experiments on rough surface using same equipment and experimental setup at the Hydraulic Modeling Laboratory of Water Science and Engineering School of the Shahid Chamran University of Ahvaz, Iran. In his experiments, the flat 


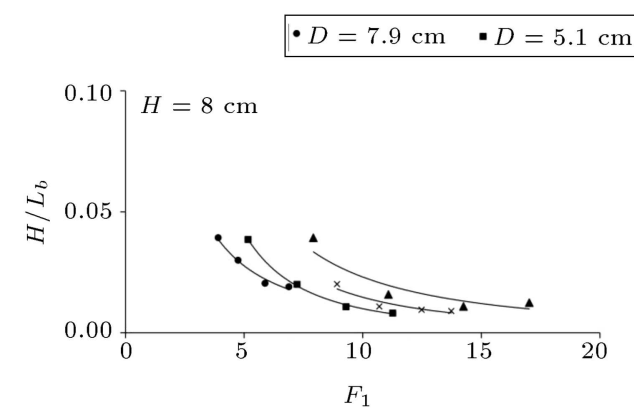

(a)

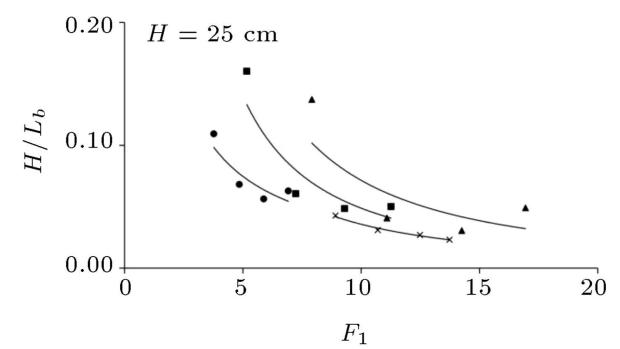

(c)

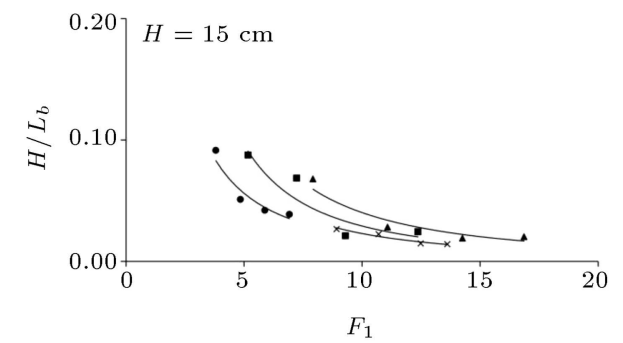

(b)

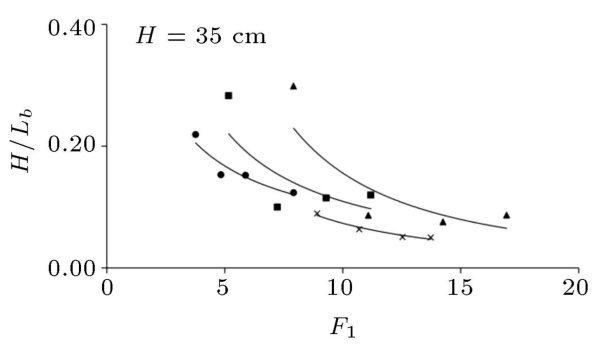

(d)

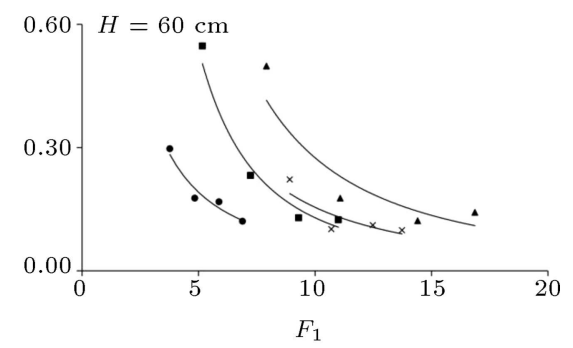

(e)

Figure 2. Variation of core length with jet Froude number.

plate surface in Figure 1 was roughened with small rectangular $2 \times 2 \times 2$ cm blocks, which were spaced $2 \mathrm{~cm}$ from each other in a chessboard pattern. The Piezometric taps were installed in the spaces between blocks. All experiments in the study of Salemnia [30] were core impact with falling heights $(H)$ of 35,60 , 90 , and $120 \mathrm{~cm}$. Results of mean dynamic pressure coefficients $\left(C_{p}\right)$ for smooth surface and falling heights of 35 and $60 \mathrm{~cm}$ in this study are compared with the rough surface results of Salemnia [30] for falling heights of 35 and $60 \mathrm{~cm}$ in Figure 4. A considerable increase in the rough surface pressure coefficients is observed in the figure due to stress of water in the space between blocks. Figure 4 shows an interesting result in terms of principal momentum as all smooth surface pressure coefficients are estimated less than 1.0, while they are all higher than 1.0 for rough surfaces. This clearly reveals that the angle of deformation of the jet over smooth surface is equal to or less than 90 degrees, while it is higher than 90 degrees over rough surface or, at least, in the space between roughness elements. Therefore, an additional force will be developed over the rough surface due to rebound of the jet momentum.

\subsection{Mathematical modeling}

As stated before, the jet Froude number is a unique parameter to designate the jet diameter and velocity, and therefore, the jet state of impact. Figure 5 shows variation of mean pressure coefficient as a result of vertical jet core impact on rough and smooth surfaces for the entire tested falling heights in this study as well as the reported mean pressure coefficients in Salemnia [30]. On average, the figure illustrates an increase in mean pressure coefficient from 0.6 to 0.9 with increase in the jet Froude number for the smooth surface and from 1.2 to 1.4 for rough surface.

Considering the significance of the jet Froude number, two Froude number based equations correlate in the estimation of the mean dynamic pressure coefficients for impact of vertical jet core on smooth and rough plane surfaces as follows:

For smooth surfaces:

$$
C_{p}=0.39 F_{1}^{0.3}, \quad R^{2}=0.74 .
$$

For rough surfaces:

$$
C_{p}=1.01 F_{1}^{0.13}, \quad R^{2}=0.61 .
$$




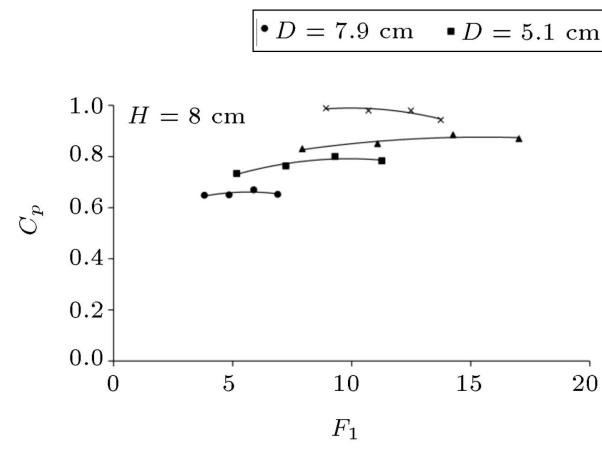

(a)

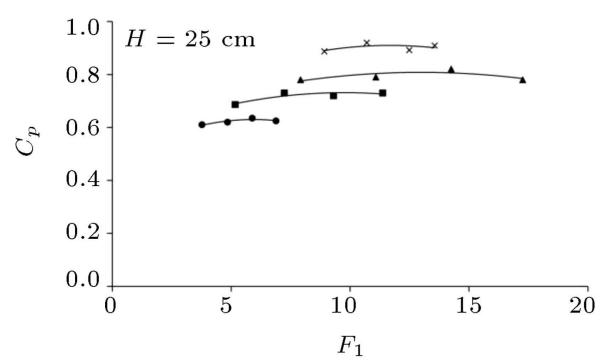

(c)

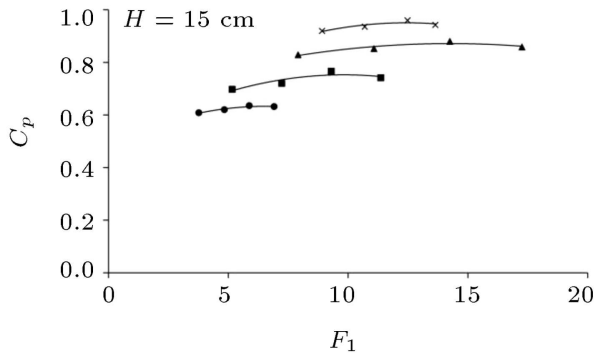

(b)

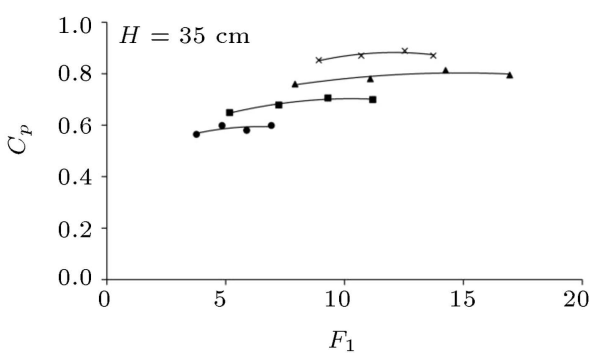

(d)

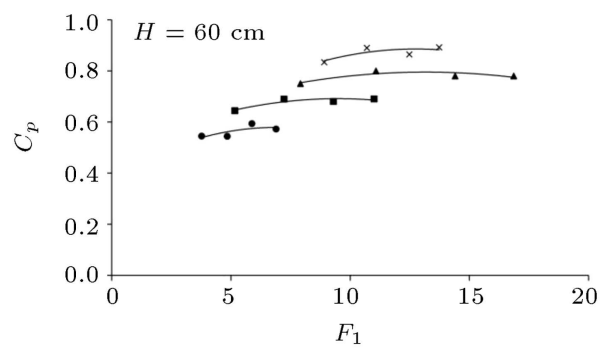

(e)

Figure 3. Mean pressure coefficient $\left(C_{p}\right)$ verses Froude number for different jet diameters.

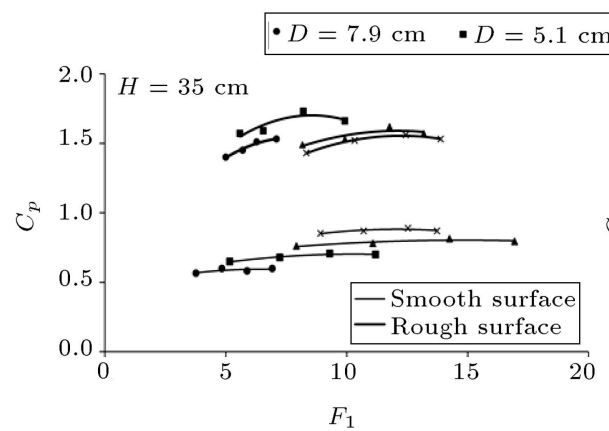

(a)

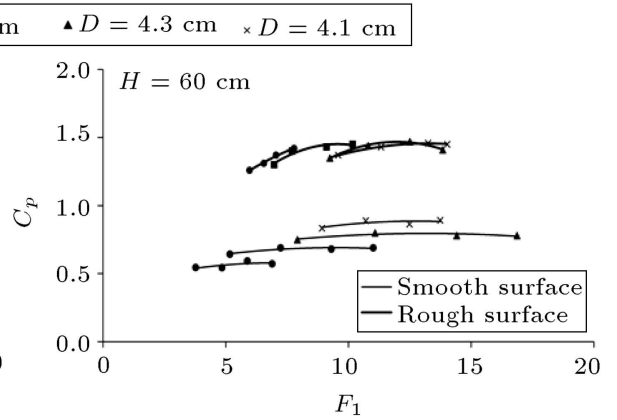

(b)

Figure 4. Comparison of mean dynamic pressure coefficients for rough and smooth surfaces: (a) $H=35$ for smooth and rough surfaces, and (b) $H=60$ for smooth and rough surfaces.

Eqs. (9) and (10) along with Eqs. (7) and (8) can be used in practice to estimate jet core impact force (i.e., mean dynamic pressure head, $H_{m}$ ) on smooth and rough plane surfaces when simple measureable parameters of the jet issuing velocity and diameter as well as falling height of $(H)$ are known.

\subsection{Turbulence intensity effects}

Turbulence intensity is known as the main parameter to break the jet core and determine the jet breakup length. Using Eqs. (2) to (8) and experimental results of the present study, the jet breakup length $\left(H / L_{b}\right)$ and turbulence intensity $\left(T_{u}\right)$ are calculated. A power 


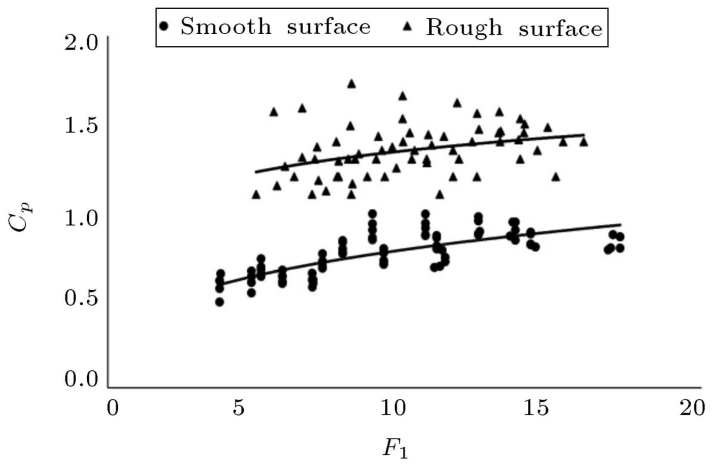

Figure 5. Variation of mean dynamic pressure coefficient with jet Froude number.

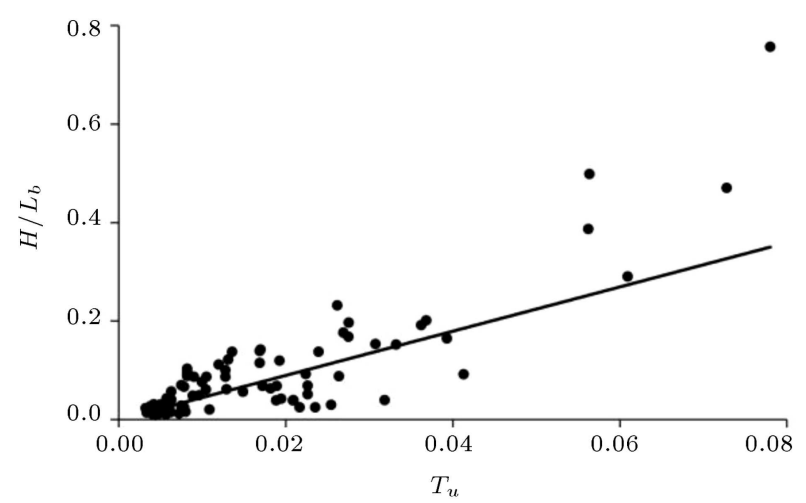

Figure 6. Relationship of turbulence intensity coefficient and jet breakup length.

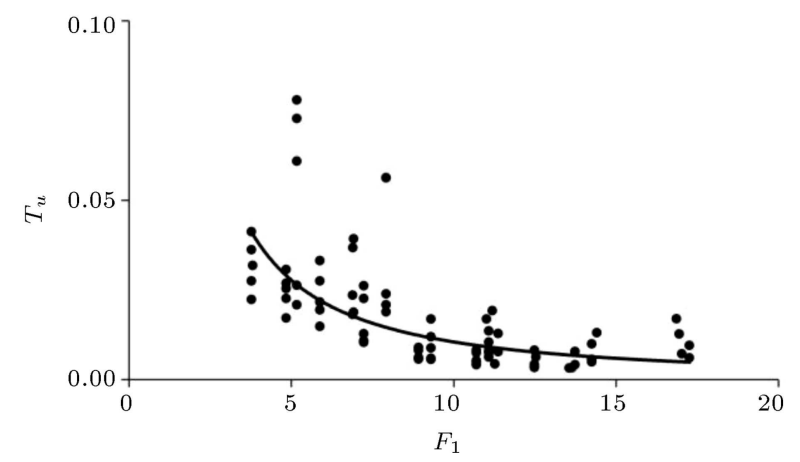

Figure 7. Effect of jet Froude number on turbulence intensity coefficient.

regression of these parameters approximates a linear line as shown in Figure 6. This confirms significant reduction in the jet breakup length with increase in the turbulence intensity for a particular falling height $(H)$.

In addition, Figure 7 is presented to assess jet Froude number effect on turbulence intensity. The figure reveals smaller effect of turbulence intensity on the jets with higher Froude number. This concurs with the results in Figure 2, which present a larger breakup length (or core length) for the jets with higher Froude number. This is true because jet Reynolds number is low in large Froude number jets, and the jet is more stable against turbulence and breaking.
Table 1. The correlation coefficient matrix between single parameters.

\begin{tabular}{cccccc}
\hline Parameters & $\boldsymbol{T}_{\boldsymbol{u}}$ & $\boldsymbol{F}_{\mathbf{1}}$ & $\boldsymbol{H}(\mathbf{m})$ & $\boldsymbol{D}(\mathbf{m})$ & $\boldsymbol{L}_{\boldsymbol{b}}$ \\
\hline$T_{u}$ & - & $-0.7^{\mathrm{a}}$ & 0.317 & $0.623^{\mathrm{a}}$ & $-0.936^{\mathrm{a}}$ \\
$F_{1}$ & - & - & $-0.006^{\mathrm{a}}$ & $-0.723^{\mathrm{a}}$ & $0.651^{\mathrm{a}}$ \\
$D(\mathrm{~m})$ & - & - & - & - & $-0.478^{\mathrm{a}}$ \\
\hline &
\end{tabular}

\subsection{Sensitivity of parameters}

To determine effect of different parameters on the jet breakup length, a cross correlation of single parameters is performed by SPSS package and results are shown in Table 1. The table shows significant correlation of the breakup length with turbulence intensity, jet diameter, and the jet Froude number. As shown before, the Froude number presents the entire effects of the jet diameter as well as the issuing jet velocity. However, the turbulence intensity shows to be the most significant parameter, which agrees with the result of Ervine and Falvey [12]. The negative sign means decrease in breakup length with increase in turbulence intensity.

Based on Ervin and Falvey's (1987) results, ratio of breakup length to nozzle diameter $\left(L_{b} / D\right)$ varies from 50 to 100 for turbulence intensity $\left(T_{u}\right)$ of 0.03 0.08 , and from 100 to 300 for $T_{u}$ less than 0.03 . In this study, $T_{u}$ varies from 0.01 to 0.08 , and $L_{b} / D$ varies from 40 and 220. Considering the experimental uncertainties, results of this study fall within a reasonable range of Ervin and Folvey's (1987) results. However, it is worth noting that different ranges of variation of $L_{b} / D$ with $T_{u}$ are reported in Castillo and Puertas [16].

\section{Conclusions}

Experiments were conducted to determine the effect of vertical jet Froude number on core impact pressure over smooth and rough plane surfaces, as well as on the jet core length and turbulence intensity. The measured mean dynamic pressures and calculated pressure coefficients for a rough surface were around one and half times higher than those for the smooth surface. This was due to stress of water within the space between roughness elements and rebound of the jet momentum. The jet Froude number was shown to be the principal parameter to designate the jet state of impact and the jet core length. The pressure coefficient increased from 0.6 to 0.9 with increase in the jet Froude number for the smooth surface and from 1.2 to 1.4 for the rough surface. Two Froude number based equations correlated in the calculation of the jet core impact pressure coefficient on smooth and rough plane surfaces. The equations could be used in practice to estimate mean dynamic pressure with simple measurable parameters of the jet diameter 
and velocity as well as falling height. In addition, an increase in the jet core length was observed with increase in the jet Froude number or in fact, decrease in the jet diameter for a particular jet velocity. This was due to the increase in jet stability as a result of decrease in the jet Reynolds number and thus, decrease in turbulence intensity. Single correlation of involved parameters revealed that turbulence intensity was the most effective parameter on the reduction in the jet breakup length.

\section{Acknowledgement}

The authors would like to acknowledge the helps of Shahid Chamran University of Ahwaz and the Centre of Excellence on Operation Management of Irrigation and Drainage Networks of Iran in the experiments.

\section{Nomenclature}

$L_{b} \quad$ Jet breakup length, or jet core length

$T_{u} \quad$ Turbulence intensity coefficient

$H \quad$ Falling height

$H_{o} \quad$ Solid body zone of the issuing jet

$\xi \quad$ Turbulent surface disorder

$X \quad$ Vertical direction from $H_{o}$ to $L_{b}$

$D_{o} \quad$ Nozzle diameter

$F_{1} \quad$ Jet Froude number

$g \quad$ Acceleration due to gravity

$V \quad$ Average issuing jet velocity

C Turbulence parameter

$u^{\prime} \quad$ Root mean square of velocity fluctuation

$C_{p} \quad$ Mean dynamic pressure coefficient

$H_{m} \quad$ Mean jet dynamic pressure head

$V_{j} \quad$ Jet velocity immediately before impact

$u \quad$ Instantaneous jet velocity

$h \quad$ Instantaneous pressure head of impact

\section{References}

1. Fathi-Moghadam, M. "A discussion on the model test report of the Dez dam low level outlets", Report No. P15466.00, produced by Acres International in association with Dezab Consulting Engineers submitted to the Khuzistan Water and Power Authority (KWPA), Ministry of Energy of Iran (2004).

2. Blair, H.K. and Rhone, T.J. Design of Small Dams, Chapter 10, Water Resources Technical Publication, U.S.B.R., Washington, USA (1977).

3. Kawakami, K. "A study on the computation of horizontal distance of jet issued from ski-jump spillway", Proceedings of the Japan Society of Civil Engineers, 219, pp. 37-44 (1973).
4. Lencaster, A. "Free overflow spillway. Engineering and design principle", Report No. 174, National Lab for Civil Engineering, Portugal, Lisbon (1961).

5. Cola, R. "Energy dissipation of a high-velocity vertical jet entering a basin", Proceedings of the 11th IAHR Congress, Leningrad, Russia (1965).

6. Beltaos, S. and Rajaratnam, N. "Plane turbulent impinging jets", Journal of Hydraulic Research, 11(1), pp. 29-59 (1973).

7. Beltaos, S. and Rajaratnam, N. "Impinging circular turbulent jets", Journal of Hydraulic Division (ASCE), 100, pp. 1313-1328 (1974).

8. Annandale, G.W., Scour Technology, Mechanism and Engineering Practice, McGraw-Hill, New York, USA (2006).

9. Castillo, L. "Experimental and numerical methodology for the characterization of the pressures in the hydraulic energy dissipators" [Metodología experimental y numérica para la caracterización del campo de presiones en los disipadores de energía hidráulica], $\mathrm{PhD}$ Thesis, Polytechnic University of Catalonia, Spain, Hydraulics (1989).

10. Castillo, L.G. "Pressures characterization of undeveloped and developed jets in shallow and deep pool", In Proceedings of the Congress-International Association for Hydraulic Research, 32(2), p. 645 (2007).

11. Manso, P.A., Bollaert, E.F.R., and Schleiss, A.J. "Impact pressure of turbulent high-velocity jets plunging in pools with flat bottom", Experiments in Fluids, 42(1), pp. 49-60 (2007).

12. Ervine, D.A. and Falvey, H.T. "Behavior of turbulent jets in atmosphere and in Plunge Pools", In Proceedings of the Institution of the Civil Engineering, 83, pp. 295-314 (1987).

13. Ervine, D.A., Falvey, H.T., and Withers, W. "Pressure fluctuation on plunge pool floors", Journal of Hydraulic Research, 35(2), pp. 257-279 (1997).

14. Duarte, R., Schleiss, A.J., and Pinheiro, A. "Influence of jet aeration on pressures around a block embedded in a plunge pool bottom", Environmental Fluid Mechanics, 15(3), pp. 673-693 (2015).

15. Castillo, L.G. "Parametrical analysis of the ultimate scour and mean dynamic pressures at plunge pools", International Workshop on Rock Scour Due to High Velocity Jets, EPFL, Swiss (2002).

16. Castillo, L.G. and Puertas, D.J. "Discussion: Scour of rock due to the impact of plunging high velocity jets. Part I: A state-of-the art review (Bollaert, E. and Schleiss, A. 2003)", Journal of Hydraulic Research, 41(5), pp. 451-464 (2004).

17. Bollaert, E. and Schleiss, A. "Physically based model for evaluation of rock scour due to high-velocity jet impact", Journal of Hydraulic Engineering, 131(3), pp. 153-165 (2005).

18. Bollaert, E. and Schleiss, A. "Scour of rock due to the impact of plunging high velocity jets Part II: 
Experimental results of dynamic pressures at pool bottoms and in one-and two-dimensional closed end rock joints", Journal of Hydraulic Research, 41(5), pp. 465-480 (2003).

19. Ghaneeizad, S.M., Atkinson, J.F., and Bennett, S.J. "Effect of flow confinement on the hydrodynamics of circular impinging jets: implications for erosion assessment", Journal of Environmental Fluid Mechanics, 15(1), pp. 1-25 (2015).

20. Kerman-Nejad, J., Fathi-Moghadam, M., Lashkarara, B., and Haghighipour, S. "Dynamic pressure of filip bucket jet", World Applied Sciences Journal, 12(8), pp. 1165-1171 (2011).

21. Puertas, J. "Hydraulic design criteria of energy dissipation basins in arch dams" [Criterios hidráulicos para el diseño de cuencos de disipación de energía en presas bóveda con vertido libre por coronación], $\mathrm{PhD}$ Thesis, Polytechnic University of Catalonia, Spain (1994).

22. Castillo, L.G. "Aerated jets and pressure fluctuation in plunge pools", In Proceedings of the 7th International Conference on Hydroscience and Engineering (ICHE), Philadelphia, USA (2006).

23. Castillo, L.G., Carrillo, J.M., and Blázquez, A. "Plunge pool dynamic pressures: a temporal analysis in the nappe flow case", Journal of Hydraulic Research, 53(1), pp. 101-118 (2014).

24. Castillo, L.G., Carrillo, J.M., and Bombardelli, F.A. "Distribution of mean flow and turbulence statistics in plunge pools", Journal of Hydroinformatics, 19(2), pp. 173-190 (2017).

25. Castillo, L.G. and Carrillo, J.M. "Comparison of methods to estimate the scour downstream of a ski jump", International Journal of Multiphase Flow, 92, pp. $171-180$ (2017).

26. Castillo, L.G. and Carrillo, J.M. "Scour, velocities and pressures evaluations produced by spillway and outlets of dam", Journal of Water, 8(3), p. 68 (2016).

27. Li, K.W., Pan, Y.W., and Liao, J.J. "A comprehensive mechanics-based model to describe bedrock river erosion by plucking in a jointed rock mass", Environmental Earth Sciences, 75(6), pp. 1-17 (2016).
28. Davies, J.T., Turbulence Phenomena, Academic Press, New York (1972).

29. Arndt, R.E.A. and Ippen, A.T. "Turbulence measurements in liquids using an improved total pressure probe", Journal of Hydraulic Research, 8(2), pp. 131157 (1970).

30. Salemnia, A. "Dynamic pressure of vertical and circular free water jets on rough surfaces", M.Sc. Thesis, Shahid Chamran University, Ahvaz, Iran (2012).

\section{Biographies}

Manoochehr Fathi-Moghadam received his BSc degree in Irrigation Engineering in 1972 from Shahid Chamran University, his MSc degree in Engineering Sciences in 1980 from University of Arkansas, USA, and his $\mathrm{PhD}$ degree in Civil Engineering in 1996 from University of Waterloo, Canada. He is currently Professor of Hydraulic Structures in the School of Water Science and Engineering at Shahid Chamran University of Ahvaz. His publications include two books and more than a hundred papers in the recognized journals. His research interests include open channel hydraulics, closed conduits, turbomachinery, and transient flow.

Amin Salemnia received his BSc degree in Water Engineering in 2010 and his MSc degree in Hydraulic Structures in 2012 from Shahid Chamran University. He is currently PhD candidate of Hydraulic Structures at Sari Agricultural Science and Natural Resources University. His research interests include open channel hydraulics and design of hydraulic structures.

Sajad Kiani received his BSc degree in Water Engineering in 2011 from Shahrood University of Technology, with the first rank, and his MSc degree in Hydraulic Structures in 2013 from University of Tehran. He is currently PhD candidate of Hydraulic Structures at Shahid Chamran University. His research interests include open channel hydraulics, design of hydraulic structures, and unsteady flow in closed conduits. 